\title{
Mouvances et Jointures. Du manuscrit au texte médiéval, textes réunis par Milena Mikhaillova
}

\section{Paola Cifarelli}

\section{(2) OpenEdition}

1 Journals

\section{Édition électronique}

URL : https://journals.openedition.org/studifrancesi/25987

DOI : 10.4000/studifrancesi.25987

ISSN : 2421-5856

Éditeur

Rosenberg \& Sellier

\section{Édition imprimée}

Date de publication : 1 avril 2007

Pagination : 153

ISSN : 0039-2944

\section{Référence électronique}

Paola Cifarelli, «Mouvances et Jointures. Du manuscrit au texte médiéval, textes réunis par Milena

Mikhaillova », Studi Francesi [En ligne], 151 (LI | I) | 2007, mis en ligne le 30 novembre 2015, consulté le 23 novembre 2021. URL : http://journals.openedition.org/studifrancesi/25987 ; DOI : https://doi.org/ $10.4000 /$ studifrancesi.25987

Ce document a été généré automatiquement le 23 novembre 2021.

\section{(c)}

Studi Francesi è distribuita con Licenza Creative Commons Attribuzione - Non commerciale - Non opere derivate 4.0 Internazionale. 


\title{
Mouvances et Jointures. Du manuscrit au texte médiéval, textes réunis par Milena Mikhaillova
}

\author{
Paola Cifarelli
}

\section{RÉFÉRENCE}

Mouvances et Jointures. Du manuscrit au texte médiéval, textes réunis par Milena MIKHAïLOVA, Orléans, Paradigme, 2005 («Medievalia», 55), pp. 334.

1 Les contributions réunies dans ce volume s'interrogent sur la flexibilité et la mobilité qui caractérisent le texte au Moyen Âge à plusieurs niveaux, en étudiant en particulier les retombées de ces phénomènes sur la création littéraire et les choix esthétiques. Parmi les travaux consacrés aux textes médiévaux, pour la plupart focalisés sur le célèbre manuscrit 837 de la BnF (dont nous rendons compte dans la section Medioevo), trois articles concernent le $\mathrm{XV}^{\mathrm{e}}$ siècle finissant.

2 Nancy Freeman REgALAdo ('Le Romant de la Rose moralisé' de Jean Molinet. Alchimie d'une lecture méditative, pp. 97-116) se penche sur un texte que Molinet acheva autour de 1500 et fit paraître sous la double forme manuscrite et imprimée. L'A. se propose d'analyser les ‘jointures’ que Molinet avait prévues pour son œuvre, divisée en chapitres intercalés de 'moralités'. Destiné à Philippe de Clèves, cousin de Louis XII, et au public laïque de l'éditeur Vérard, ce texte est une 'mise en prose' du Roman de la Rose visant à rendre ce dernier plus accessible, non seulement par un rajeunissement et une simplification de la langue, mais aussi grâce à une mise en page astucieuse et aux moralités, qui imposent un rythme de lecture particulier. Une approche nouvelle de cet ouvrage souvent dénigré par la critique permet de montrer que l'enseignement de la pratique de lecture méditative à partir d'une matière profane et mondaine est le but principal de son auteur. 
Gabriella PARUSSA (Le manuscrit 1131 de la Bibliothèque Sainte-Geneviève de Paris: un montage signifiant?, pp. 229-251) revient sur un célèbre manuscrit contenant neuf mystères des $\mathrm{XIV}^{\mathrm{e}}$ et $\mathrm{XV}^{\mathrm{e}}$ siècles et composé pour une confrérie parisienne, pour en proposer une étude d'ensemble et montrer que l'organisation interne de ce codex, loin d'être inexistante, révèle un projet précis. En s'appuyant sur l'étude des didascalies, sur l'analyse linguistique, la récurrence de certains personnages, la toponymie, G.P. fait apparaître un jeu de références croisées permettant d'affirmer, d'un côté, que ce manuscrit est «un grand ensemble [...] qui veut signifier dans son intégralité la translation de l'Église de Jérusalem à Rome et à la région parisienne», et d'autre part que le copiste du manuscrit 1131, clerc de l'Abbaye de Sainte-Geneviève, s'est inspiré d'un légendier de la famille $\mathrm{D}$ pour déterminer la succession des textes dans le codex.

Christopher LUCKEN (Le poème délivré. Le désœuvrement de Fortune et le passe-temps de l'écriture dans le manuscrit personnel de Charles d'Orléans, pp. 283-313) examine lui aussi un manuscrit célèbre (BnF fr. 25458) et longuement étudié par G. Paris, pour avancer l'hypothèse qu'il possède sa propre logique dans la forme et dans la succession des textes telle qu'elle apparaît actuellement, plutôt que l'ordre chronologique dans lequel les poèmes y ont été copiés. L'insertion des poèmes à partir d'un premier ensemble réalisé en Angleterre reflète l'évolution subie par le projet poétique du prince, qui s'éloigne de plus en plus d'un principe d'organisation traditionnel et harmonieux: la désharmonie et l'inachèvement remplaceraient donc la perspective temporelle et le scénario romanesque, tandis que le livre, autrefois conçu comme objet 'public', devient le lieu de la mémoire, et donc de l'intimité. Quelques suggestions pour une nouvelle édition de ce manuscrit achèvent cette étude. 